\title{
The fine structure of chordoma with particular reference to the physaliphorous cell
}

\author{
I. FRIEDMANN, D. F. N. HARRISON, AND E. S. BIRD \\ From the Department of Pathology, the Institute of Laryngology and Otology, \\ University of London
}

SYNOPSIS A chordoma was examined by electron microscopy. It was composed of stellate an physaliphorous cells. The fine structure of these cells is described. Transitional type cells are als $\overrightarrow{\Theta r}$ described and it is suggested that the physaliphorous cells develop from the stellate cells through $\mathrm{N}$ process of vacuolation. Two types of vacuoles are described, 'smooth-walled' and 'villous' endowe with numerous structureless microvilli. Some observations on stained sections are discussed.

The pathological and clinical aspects of this uncommon neoplasm have attracted considerable interest and over 300 cases have been reported in the literature. Chordoma was first described by Virchow (1857). Müller (1858) demonstrated the notochordal origin of chordoma and this was confirmed by Ribbert (1894). Stewart (1922) and Cappell (1928) in two classical papers provided much of our knowledge of the light microscopy of the tumour and subsequent authors found little to add to their findings.

More recently Crawford (1958) examined the staining reactions of the tumour and provided a helpful method for distinguishing between chordomatous and cartilaginous ground substance. The sharpest histological distinction was achieved by the phosphotungstic-acid-haematoxylin and the reticulin stains. With both these techniques chordomatous matrix remains unstained whereas cartilaginous ground substance is strongly impregnated.

Briefly the chordoma consists of large voluminous cells, occurring singly or in aggregates, which are separated by a homogeneous amorphous mucoid or gelatinous intercellular ground substance in which the neoplastic cells are immersed. The vacuolization of the cytoplasm is a distinguishing feature which gives the cell its attribute 'physaliphorous' (blister bearing). It may be so extensive that the cells seem to consist of an envelope and a nucleus only. Another type of cell has a stellate shape and no vacuoles in the granular cytoplasm. The intercellular matrix is also vacuolated and has an almost frothy appearance.

There have been two cases of nasopharyngeal chordoma in our material during the past decade, the clinical records of which were described by

Received for publication 30 October 1961.
Ormerod (1960) and Harrison (1961) respectively $\frac{\stackrel{5}{2}}{2}$ The first of these patients responded well to two large doses of radiation, the second presented with a recurrence six months after incomplete removal of a primary chordoma of the sphenoidal sinus. This recurrence offered a good opportunity to obtain suitable material for electron microscopy, and the present paper probably contains the first descriptio of the fine structure of the physaliphorous cell on chordoma.

\section{CASE REPORT}

William D., now aged 53 years, was seen at the Medica Out-patient Department, Guy's Hospital, London, iक April 1958. He complained that headache, presen intermittently for the past two years, had become much more severe during the previous six weeks.

Radiographs showed erosion of the anterior wall and floor of the sella, almost complete destruction of the sphenoidal sinuses, destruction of the adjacent lefi ethmoidal cells and possibly of the medial wall of the let superior orbital tissue. The nasopharynx was quite normal. A tentative diagnosis of a mucocele of the sphenoidal sinus was made.

On 25 May 1960 the left sphenoidal sinus was a proached by means of a Paterson's transorbital ethmoids ectomy. The whole of the anterior wall of both sinus was found to be replaced by a firm blue cystic swelling This was ruptured and the mucoid contents aspirates the cyst wall being removed as far as possible in view of the extensive loss of the surrounding bony walls. No claim is made that a radical clearance was carried out first because it was not technically feasible and second 5 because the provisional diagnosis of a mucocele appearef to be confirmed at operation. The biopsy taken from the cyst wall showed the typical features of chordom (Fig. 1). 
The patient has been seen regularly since the operation and symptoms did not return until December 1960. Tissue from the nasopharynx was then removed in the Out-patient Department of the Royal National Throat, Nose and Ear Hospital and fixed for both light and electron microscopy.

\section{LIGHT MICROSCOPY}

Sections were stained with haematoxylin and eosin, the periodic-acid-Schiff reaction, phosphotungsticacid-haematoxylin, and mucicarmine.

The pathological diagnosis was based on the presence of the characteristic physaliphorous cells separated by a matrix of ground substance which had a similar frothy vacuolated appearance to the cell cytoplasm. The physaliphorous cells were of considerable size, reaching $50 \mu$ in diameter, and distinguished by the presence of numerous clear vacuoles of varying size separated by granular eosinophilic P.A.S.-positive cytoplasm. In some parts the cells were smaller and of polygonal or stellate shape. The ground substance and the cytoplasm but not the vacuoles stained with mucicarmine and gave a positive P.A.S. reaction.

\section{ELECTRON MICROSCOPY}

METHODS Small pieces of the tumour removed under a local anaesthetic were fixed in $1 \%$ veronal-acetate buffered osmic acid containing 3\% Dextran and $0.3 \%$ sucrose and embedded in methacrylate and Vestopal W.

Ultrathin sections (silver interference colour) were cut on a Huxley type ultramicrotome and the sections mounted on Formvar or Parlodion-coated plain or carbon-coated Athene copper grids.

Unstained and stained sections were examined at $80 \mathrm{kv}$ under a Siemens Elmiskop I. Direct photographs were taken on Ilford contrasty plates at 3,000 to 10,000 direct magnifications and suitably enlarged on a Duomat enlarger.

STAINING METHODS These were based on Watson's (1958) original discovery of the use of certain heavy metals so as to enhance the contrast of the image.

The following 'stains' were employed: $1 \%$ phosphotungstic-acid in $50 \%$ alcohol, sections stained for 15 minutes; 2 or $7 \%$ uranyl-acetate in distilled water, sections stained for 15 minutes; lead-hydroxide solution prepared according to Lever's method (1960). Fresh solutions were made up every day and the sections were stained five minutes under a jar containing nitrogen gas.

\section{ELECTRON MICROSCOPE OBSERVATIONS} IN UNSTAINED SECTIONS

STELLATE CELL The stellate cells were rather large, mostly 20 to $30 \mu$ in diameter, with large, often eccentrically placed nuclei. The well-preserved elongated or round mitochondria formed densely packed layers and aggregates in the perinuclear zone (Fig. 1). The cytoplasm contained numerous profiles of rough surfaced endoplasmic cysternae scattered between the mitochondria (Figs. 1 and 2). There were groups of Golgi lamellae and vesicles forming the Golgi apparatus of the cell, usually in an area free of mitochondria. The nucleus had a well-defined double nuclear membrane and one or two hyperplastic nucleoli. There were, frequently, rounded dense patchy agglomerates of unknown nature in the nuclei of the stellate cells (Figs. 1 and 2). This description applies to the stellate cell only in its typical non-vacuolated stage.

Some stellate cells, while preserving their general pattern, displayed important changes leading more or less gradually to the formation of the physaliphorous cell. First the rough surfaced endoplasmic cysternae became dilated and clear spaces were formed surrounding the still well-preserved mitochondria (Figs. 2 and 3). These distended cysternae were outlined by ribosome granules.

Due to maturation and increased secretory activity, or degeneration, the clear spaces grew larger and coalesced to form vacuoles of varying size and shape. This appeared to be the process by which stellate cells were converted into the vacuolated physaliphorous cell.

PHYSALIPHOROUS CELL Vacuolation was the characteristic feature of the physaliphorous cells in ultrathin sections (Figs. 4 and 5). Owing to the presence of usually numerous and often very large vacuoles, the cell itself reached a size of up to $50 \mu$ and more in diameter. The large vacuoles coalesced further and occupied the greater part of the cytoplasm.

There were two types of vacuoles in the physaliphorous cell:

'Villous vacuoles' These (Fig. 5) showed microvilli projecting from the wall into the cavity of the vacuole. In ultrathin sections the vacuole contained numerous cross-sections of microvilli in addition to long projections from the cytoplasmic surface. Some of these projections appeared to be remnants of the ergastoplasmic cysternae especially in 'villous' vacuoles located within the cytoplasm. Microvilli were observed mainly in vacuoles near the cell surface. The projections were structureless and could not be mistaken for true cilia.

Smooth-walled vacuoles These (Figs. 5 and 6) were located within the cytoplasm, which contains some granular matter. Such vacuoles may lie close to the nuclear membrane and often cause indentation of the nucleus. Moreover the nucleus may also be vacuolated. 


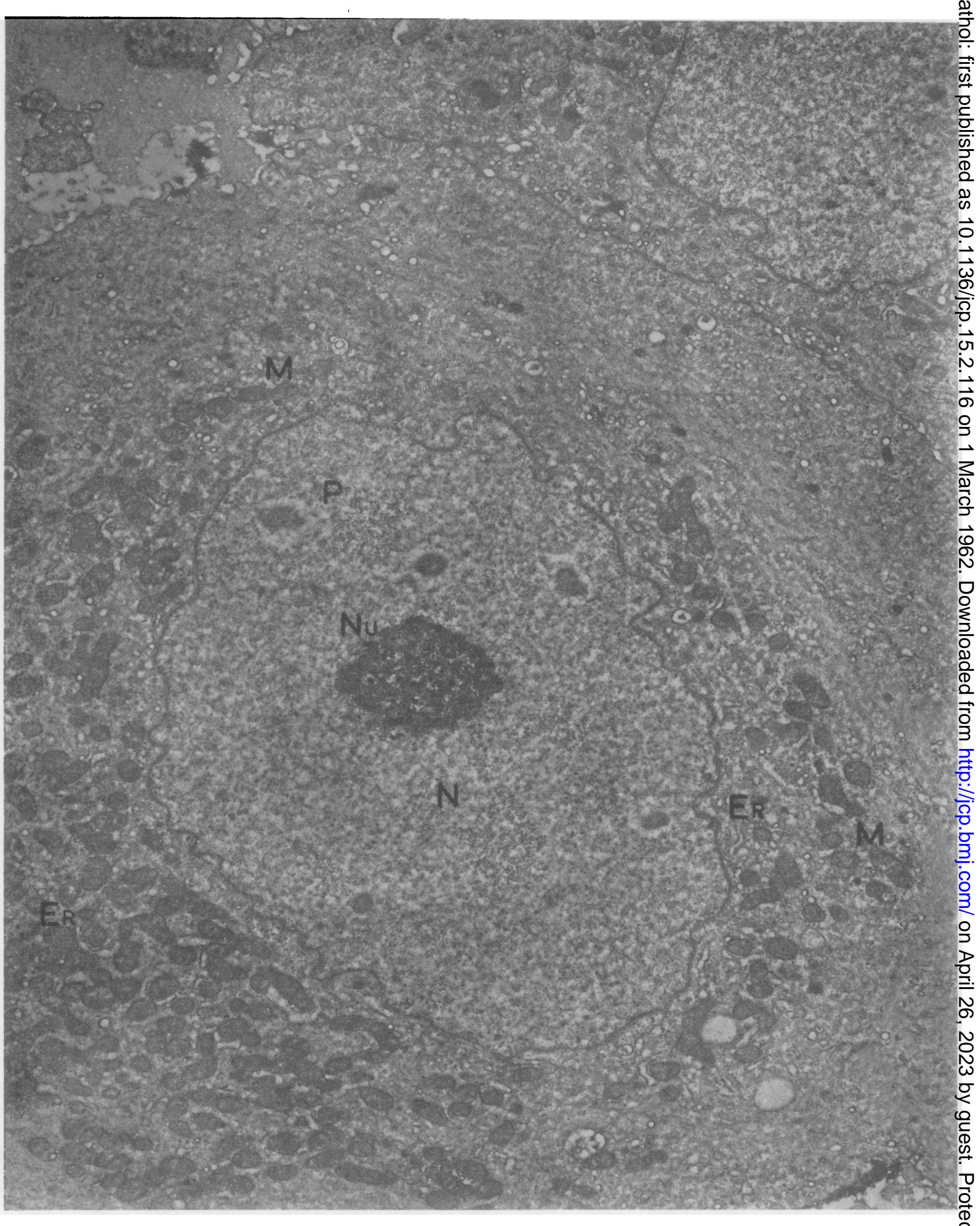

FIG. 1. Stellate cell. Note mainly perinuclear arrangement of mitochondria $(M)$, large nucleus $(N)$ with hyperplastic $\frac{?}{\mathbb{Q}}$ nucleolus $(\mathrm{Nu})$, and dark grey patches $(P)$ of unknown nature. There are numerous rough-surfaced endoplasmic cysternae $\varrho$ (Er) between the mitochondria.

EM 3844, $2 \%$ uranyl-acetate stained, EM $\times 3,000$, total $\times 13,500$. 


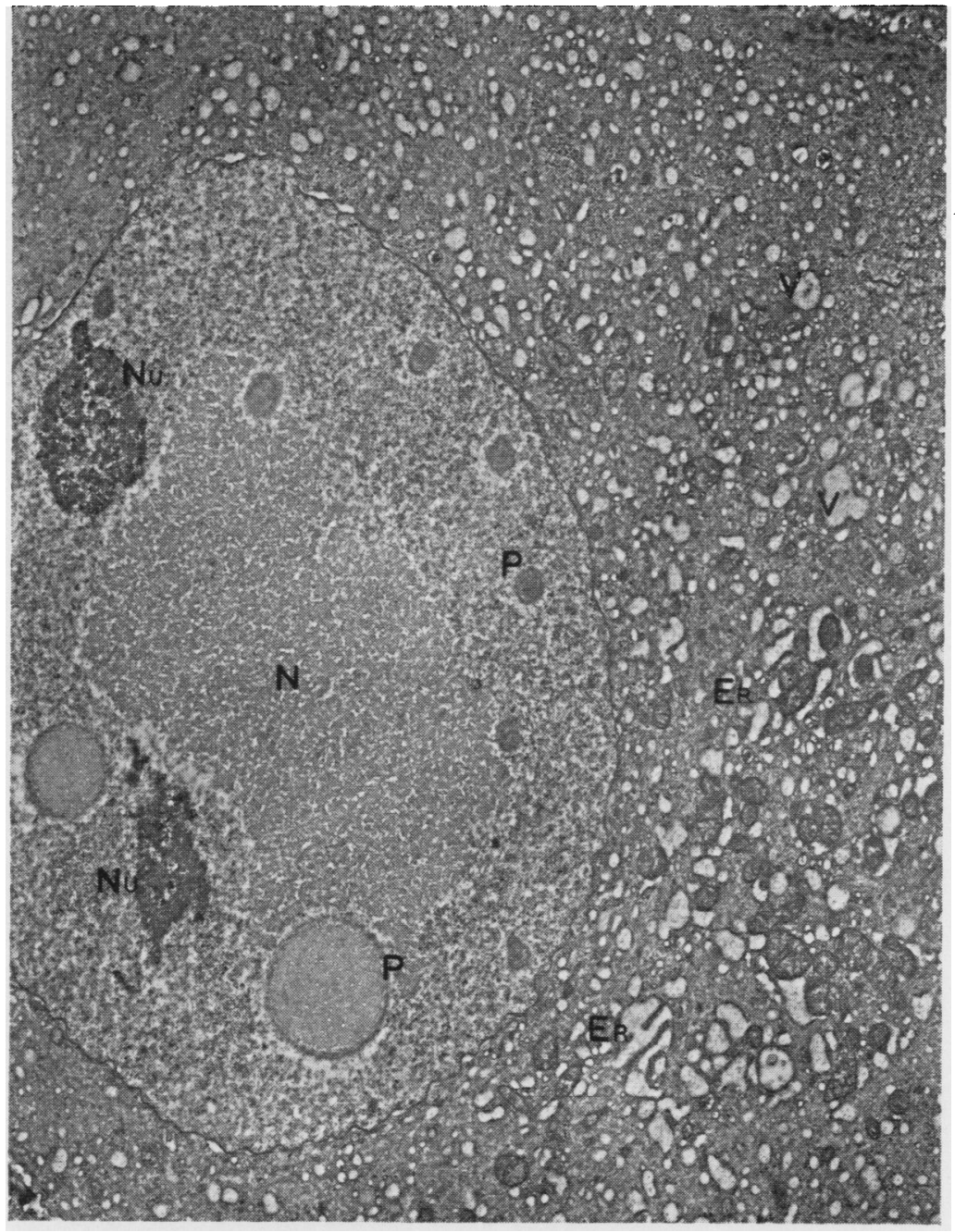

FIG. 2. Stellate cell with large numbers of well-preserved mitochondria $(M)$ aggregated around the nucleus $(N)$. There are distended rough-surfaced endoplasmic cysternae (Er) and small vacuoles $(V)$ present. Note nucleus $(N)$ with nucleoli $(\mathrm{Nu})$ and various patchy $(P)$ inclusions.

EM 3881, 2\% uranyl acetate stained, $E M \times 2,500$, total $\times$ 10,000 .

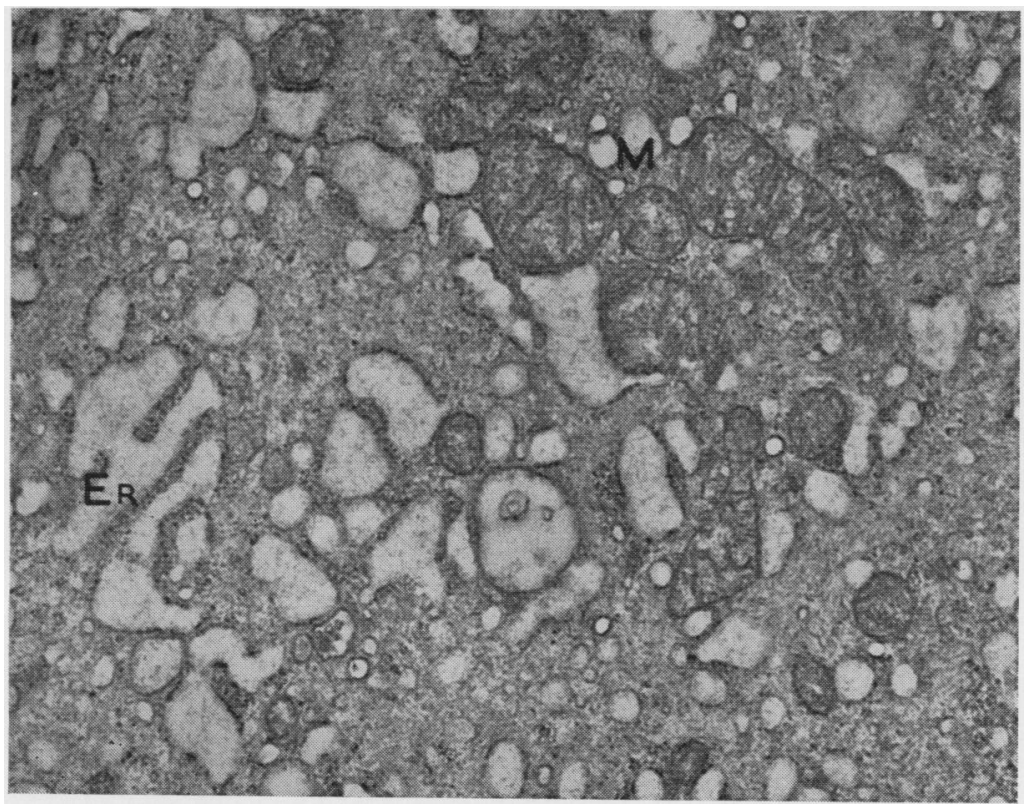

FIG. 3. Detail of cytoplasm showing distended endoplasmic cysternae (Er) and well preserved mitochondria $(M)$. Note vacuole with remnants of rough-surfaced cysternae $(V)$.

EM 3881, 2\% uranyl acetate stained, $E M \times 5,000$, total $\times$ 31,500 . 


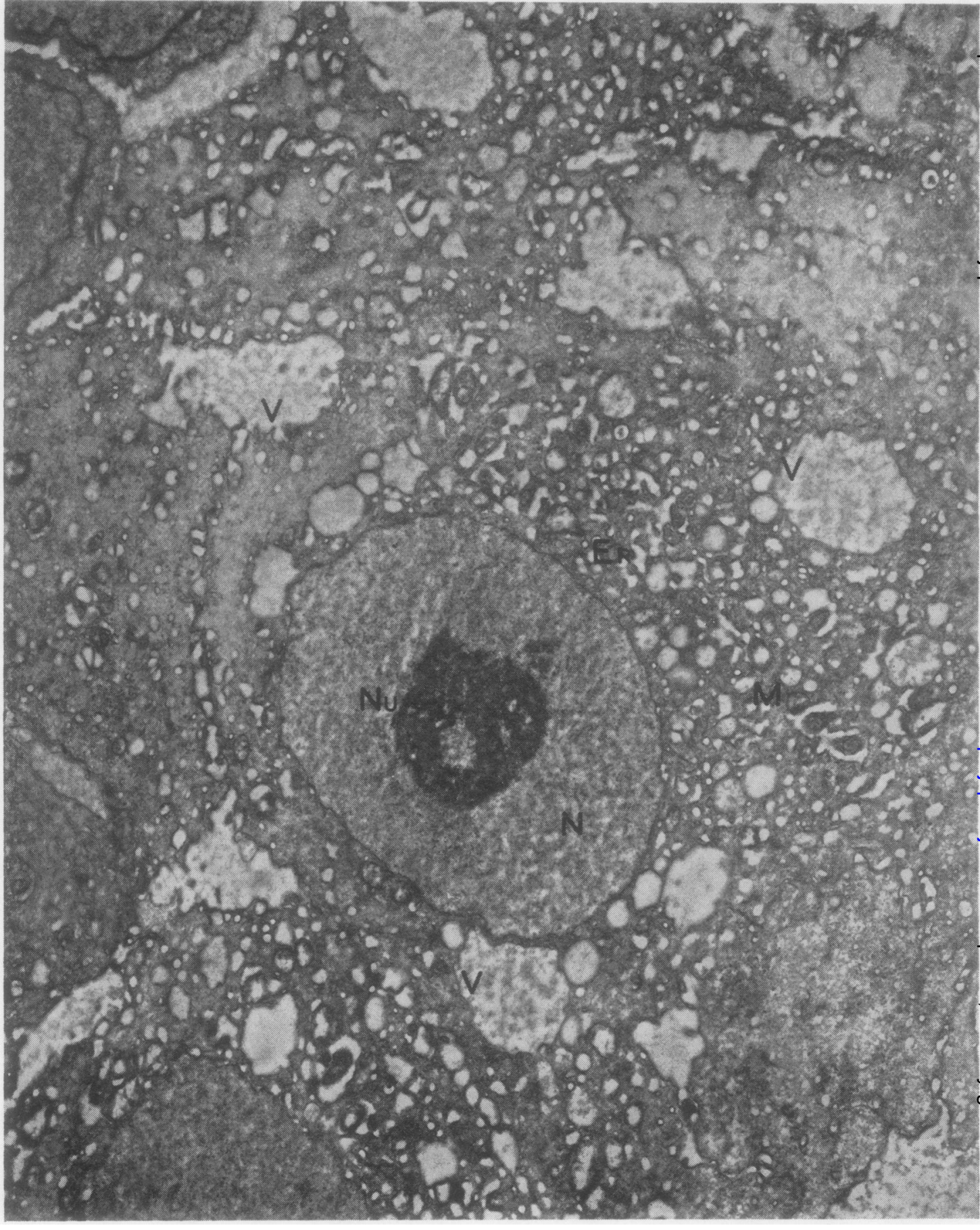

FIG. 4. Physaliphorous cell with intra- and intercellular vacuoles $(V)$ and nucleus $(N)$ with large nucleolus $(\mathrm{Nu})$. $E M 3880$, not stained, $E M \times 3,000$, total $\times 12,000$. 


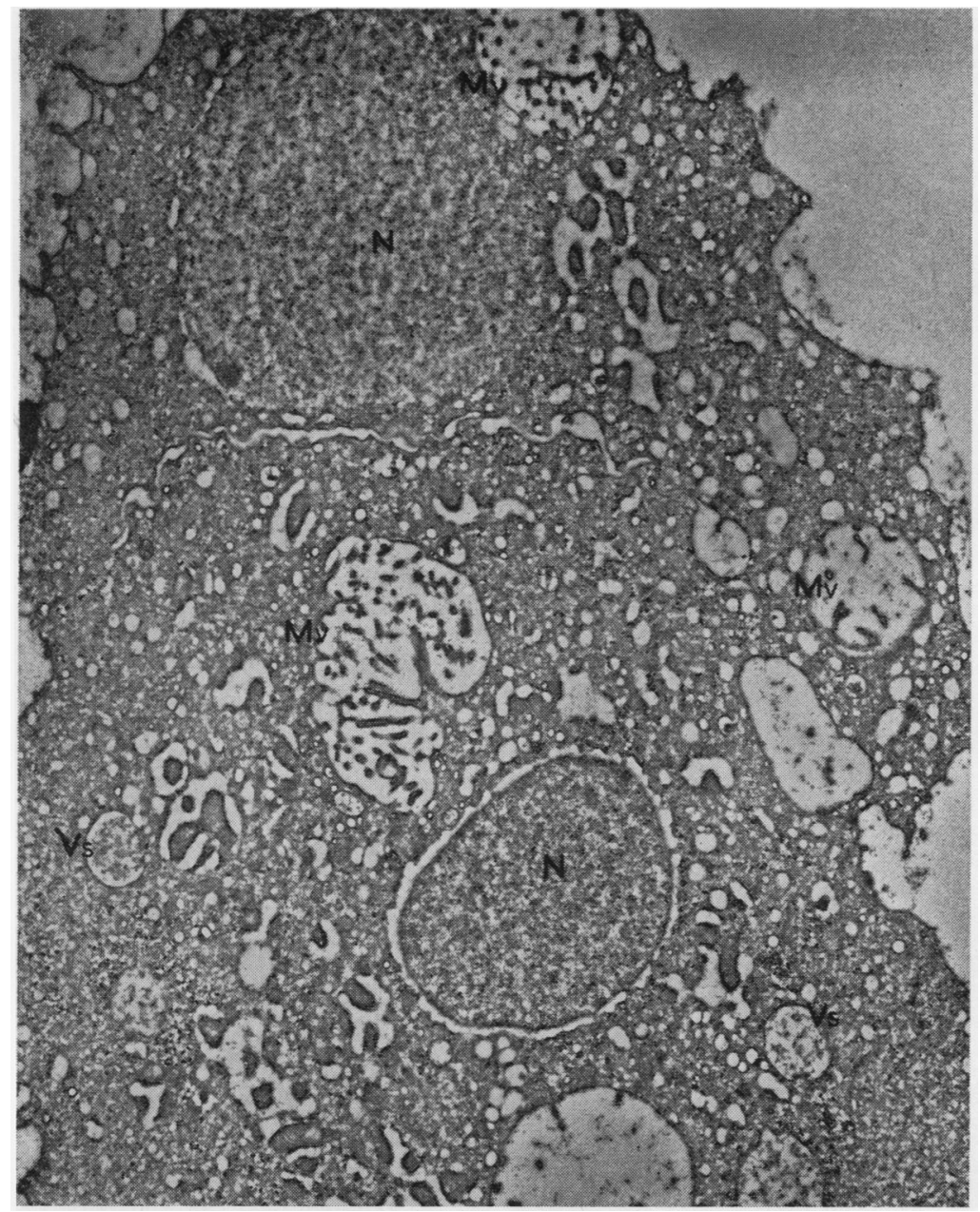

FIG. 5

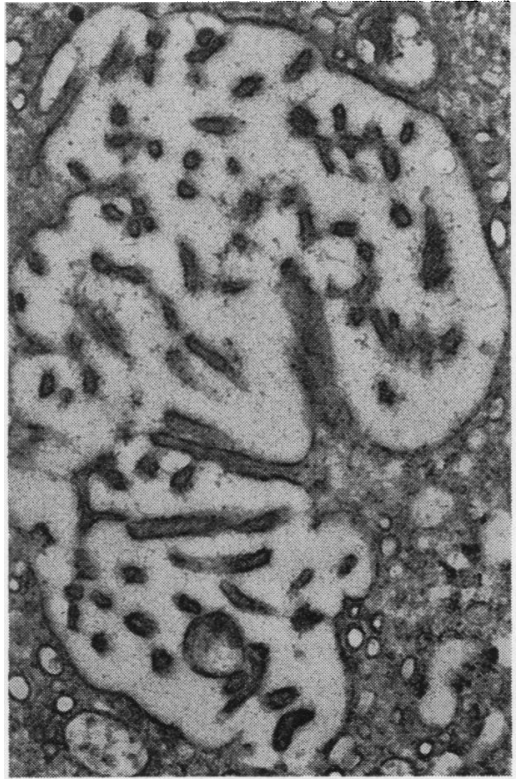

FIG. 5. Two physaliphorous cells with several large vacuoles $(V)$ in the cytoplasm. Note vacuoles with microvilli $(M v)$; also small smooth-walled vacuoles $(V s)$ and nuclei $(N)$.

FIG. 5a. Villous vacuole (as in Fig. 5). Note remnants of endoplasmic cysternae.

$E M 3882,2 \%$ uranyl acetate stained, $E M \times 2,500$, total $\times 32,500$.

FIG. 5a 


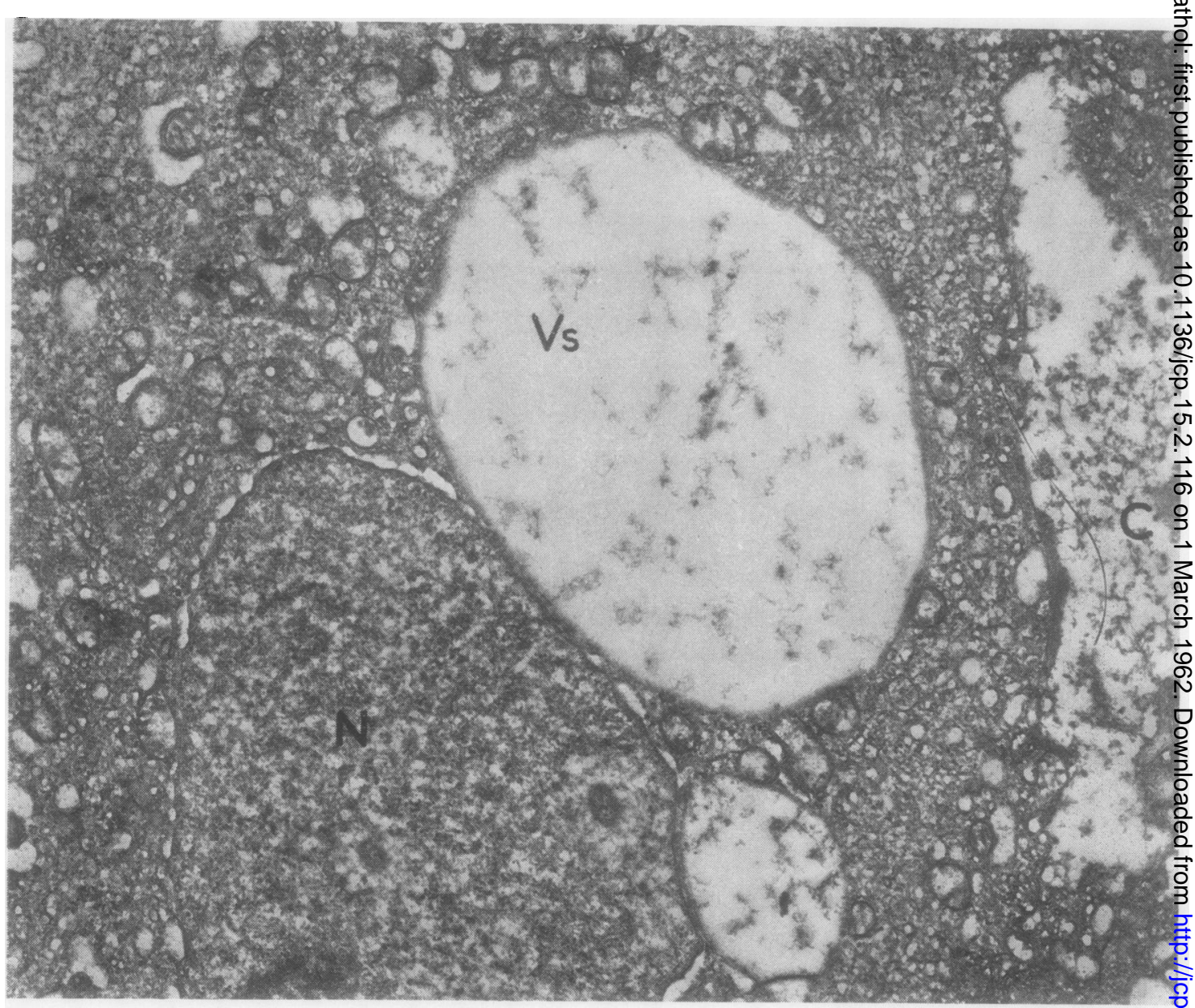

FIG. 6. Physaliphorous cell with smooth vacuoles $(V s)$ near the nucleus $(N)$; some collagen $(C)$ in intercellular spaces $E M 4248,1 \% \mathrm{~Pb}(\mathrm{OH})_{2}$ stained, $E M \times 4,000$, total $\times 14,000$.

The ground substance or matrix separating the cells contained inflammatory cells such as leucocytes and plasmacytes. Otherwise it appeared, in unstained sections, as a greyish amorphous substance.

ELECTRON MICROSCOPE OBSERVATIONS IN STAINED SECTIONS Staining methods have been employed to enhance the general contrast of the sections and to demonstrate certain substances such as collagen and glycogen.

The contrast of various organelles and other cytoplasmic and nuclear structures was markedly enhanced with all stains, but particularly in sections stained with lead-hydroxide (Watson, 1958; Lever, 1960). In addition lead-hydroxide stained up some black granules forming small groups or large aggregates. These were interpreted as glycogen.

Phosphotungstic-acid stained collagen fibres in the intercellular matrix as greyish striated bands arranged in bundles. There were also irregularl arrayed shorter fibres in the intercellular substanceos

In addition phosphotungstic-acid stained up, in some of the sections, densely packed granules in the्ज perinuclear zone of the physaliphorous cell (Figs 7 and 8). The intercellular location of this phosphotungstic-acid-positive material has suggested some other substance rather than collagen and this? is being investigated further.

\section{DISCUSSION}

The fine structure of chordoma cells has not pre $\frac{0}{8}$ viously been described. The overall pattern of the tumour as observed in electron-micrographs was thes 


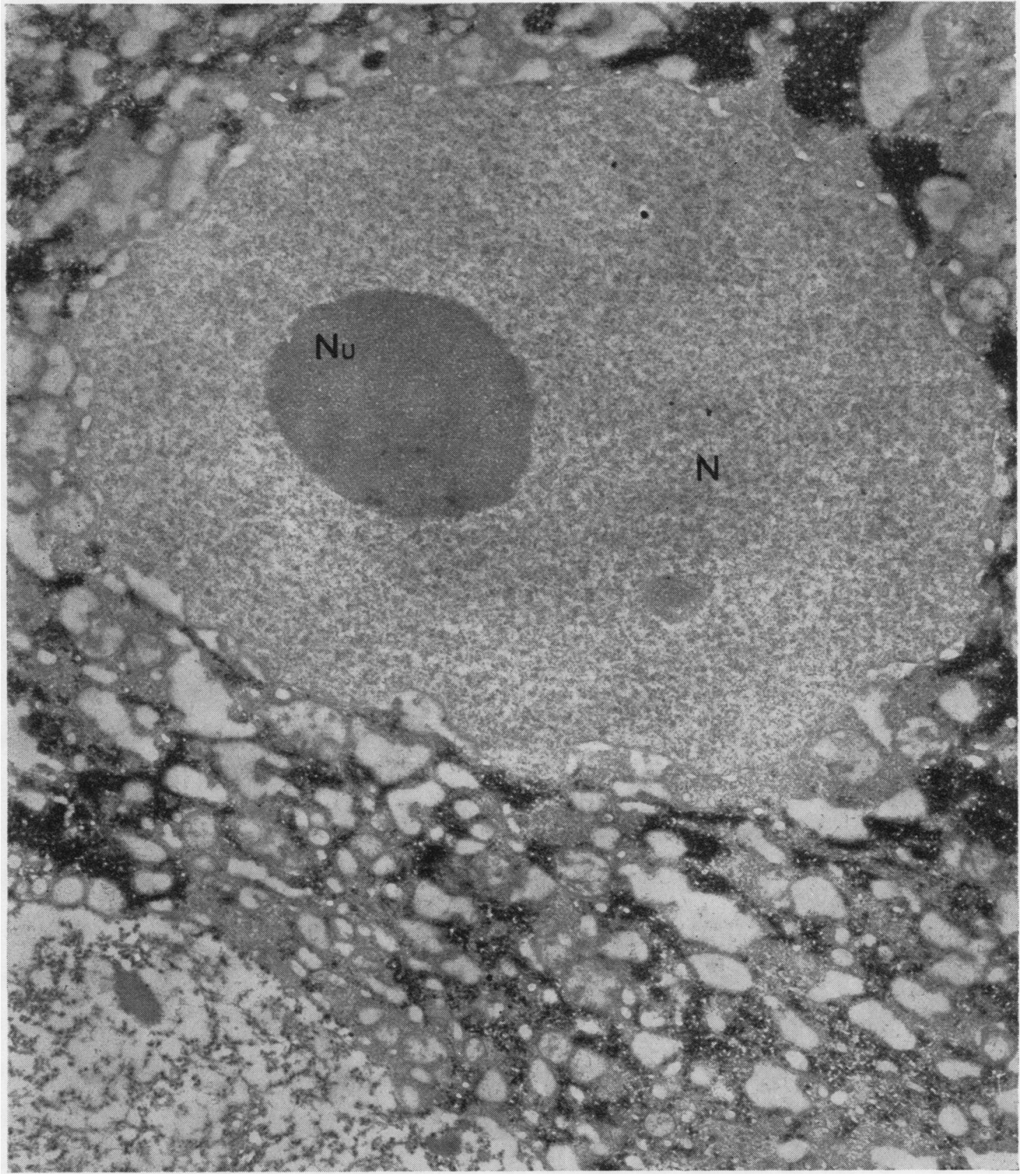

FIG. 7. Nucleus of physaliphorous cell. Note P.T.A. stained granules in the cytoplasm. EM 4239, $1 \%$ P.T.A. stained, EM $\times 5,000$, total $\times 17,500$. 


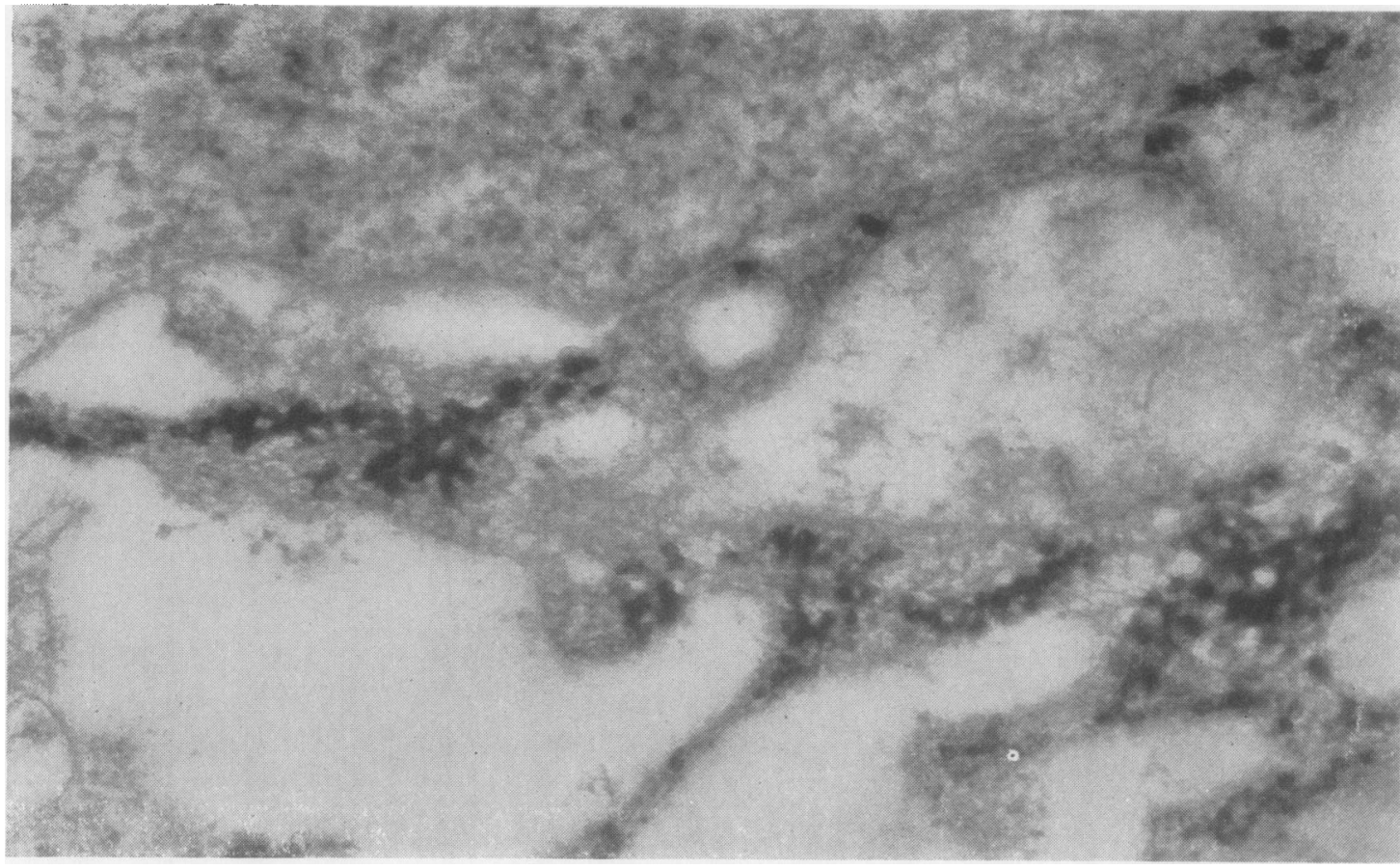

FIG. 8. Part of nucleus and P.T.A. stained granules in the cytoplasm. EM 4240, EM $\times 25,000$, total $\times 87,500$.

familiar one: isolated groups of tumour cells separated by an amorphous ground substance. There was a great variation in the size, shape, and cytoplasmic features of the neoplastic cells.

It has been customary to recognize two types of cells under the light microscope, the stellate cell and the physaliphorous cell. Similarly electron microscopy reveals two more or less characteristic patterns of the fine structure of chordoma cells. Significant transitional stages between the non-vacuolated stellate cells and the fully vacuolated physaliphorous cells were, however, observed, indicating a close relationship of these two cell types. Through a more or less gradual process of vacuolation a stellate cell is transformed into the vacuolated or physaliphorous cell. The vacuoles may be a product of hypersecretion or degeneration and develop mainly from the ergastoplasm of the stellate cell. Mitochondria do not seem to be involved in the process of vacuolation although they may undergo gradual degeneration. It should be emphasized that chordoma cells, though obviously neoplastic and malignant in character, possess large numbers of mitochondria and granular endoplasmic cysternae.

Two types of vacuoles have been observed, the villous and the smooth-walled type. In the physaliphorous cells 'villous vacuoles' were observed both within the cell and on the cell surface. The surface $\vec{P}$ vacuoles contained microvilli of the type found $\frac{3}{3}$ frequently on the surface of epithelial or other cells. In the intercellular 'villous vacuoles' the projections? appeared to be remnants of the rough-surfaced cysternae. Neither type of villus showed any internalo structure. It is interesting to note that the villous $\frac{5}{3}$ type vacuole formed inside the physaliphorous cell was similar to the "hair-lined intracytoplasmic $ᄋ$ spaces' described by Spriggs and Meek (1961) in a malignant cell obtained from the peritoneal fluid of a patient suffering from carcinoma of breast with $D$ peritoneal secondaries and ascites. Spriggs and Meek (1961) used the term 'cilia and hair-like processes' N for such structures. In our opinion the term cilium must not be applied to 'hair-like processes' which do not possess the $9+2$ pattern of longitudinal $\omega$ filaments, or some variation of this pattern, the? characteristic feature of cilia and flagella throughoutco nature (Fawcett, 1958).

Tumour cells show considerable variation of the $\stackrel{\text { ? }}{+}$ cytoplasm or cytoplasmic borders which, though not $\frac{}{T}$ specific signs of malignancy, deserve closer attention $\frac{\overrightarrow{\mathrm{D}}}{\mathrm{D}}$ than they have received in the past. The staining $\frac{\mathrm{O}}{+}$ methods furnished little fundamental information $\triangle$ on the structure and constitution of the intercellularo amorphous substance except to confirm the presenceo 
of glycogen (Iurato and Leonardelli, 1956). Crawford (1958) noted that the matrix of chordoma, contrary to that of cartilaginous matrix, does not stain with phosphotungstic-acid-haematoxylin. In ultrathin sections, however, there was a good deal of phosphotungstic-acid-positive material within the chordoma cells, the nature of which has not been established. Drochmans (1960) failed to stain glycogen with phosphotungstic-acid. The phosphotungstic-acidstained granules might be cross-sections of collagen fibres but their intracellular location advocates against this interpretation.

As this is the first case of chordoma to be studied under the electron microscope it may be expected that other examples of chordoma will be examined and that further light will be thrown on various points unanswered by our investigations.
Our thanks are due to the British Empire Cancer Campaign for a grant towards the expenses of this study. Mr. R. Nunn, A.I.M.L.T., assisted with the technical and photographic work.

\section{REFERENCES}

Cappell, D. F. (1928). J. Path. Bact., 31, 797.

Crawford, T. (1958). J. clin. Path., 11, 110.

Drochmans, P. (1960). J. biophys. biochem. Cytol., 8, 553.

Fawcett, D. W. (1958). In Frontiers in Cytology, p. 19, ed. by S L. Palay, Yale University Press, New Haven, Connecticut. Harrison, D. F. N. (1961). J. Laryng., 75, 429.

Iurato, S., and Leonardelli, G. B. (1956). Tumori, 42, 559.

Lever, J. D. (1960). Nature (Lond.), 186, 810.

Müller, H. (1858). Z. rationelle Med., 3rd series, 2, 202.

Ormerod, R. (1960). J. Laryng., 74, 245.

Ribbert, H. (1894). Zbl. allg. Path. path. Anat., 5, 457.

Spriggs, A. I., and Meek, G. A. (1961). J. Path. Bact., 82, 151.

Stewart, M. J. (1922). Ibid., 25, 40.

Virchow, R. (1857). Virchows Arch. path. Anat., 11, 79.

Watson, M. L. (1958). J. biophys. biochem. Cytol., 4, 475 and 727.

\section{Broadsheets prepared by the Association of Clinical Pathologists}

The following broadsheets (new series) are published by the Association of Clinical Pathologists. They may be obtained from Dr. R. B. H. Tierney, Pathological Laboratory, Boutport Street, Barnstaple, N. Devon. The prices include postage, but air mail will be charged extra.

3 The Detection of Barbiturates in Blood, Cerebrospinal Fluid, Urine, and Stomach Contents. 1953. L. C. NICKOLLS. 1s.

4 The Estimation of Carbon Monoxide in Blood. 1953. D. A. STANLEY. 1s.

5 The Identification of Reducing Substances in Urine by Partition Chromatography on Paper. 1953. G. B. MANNING. 1s.

6 The Paul-Bunnell Test. 1954. R. H. A. SWAIN. 1s.

7 The Papanicolaou Technique for the Detection of Malignant Cells in Sputum. 1955. F. HAMPSON. 1s.

10 Mycological Techniques: (1) Collection of Specimens. 1956. R. W. RIDDELL. 1s.

11 Mycological Techniques: (2) Cultural Isolation. 1956. R. W. RIDDELL. 1s.

12 Techniques for Demonstrating L.E. Cells. 1956. J. V. DACIE and L. S. SACKER. 1s.

13 The Identification of Serotypes of Escherichia coli Associated with Infantile Gastro-enteritis. 1956. JOAN TAYLOR. $1 \mathrm{s.}$

14 The Determination of Serum Iron and Serum Unsaturated Iron-binding Capacity. 1956. ARTHUR JORDAN. 1s.

16 Preservation of Pathological Museum Specimens. 1957. L. W. PROGER. 1s.

17 Cultural Diagnosis of Whooping-cough. 1957. B. W. LACEY. $1 \mathrm{~s}$.

18 The Rose-Waaler Test. 1957. c. L. GREENBURY. $1 \mathrm{~s}$.

19 The Laboratory Diagnosis of Fibrinogen Deficiency. 1958. R. M. HARDISTY. 1 s.
20 Investigation of Porphyrin/Porphyria. 1958. C. RIMINGTON. $1 \mathrm{~s}$.

22 Investigation of Haemolytic Anaemia. 1959. J. G. SELWYN. 1s.

23 The Dried Disc Technique for Bacterial Sensitivity Tests. 1959. R. W. FAIRBROTHER and J. C. SHERRIS. 1s.

24 Safe Handling of Radioactive Tissues in the Laboratory and Post-mortem Room. 1959. R. C. CURRAN. $1 \mathrm{~s}$.

26 The Periodic Acid-Schiff Reaction. 1959. A. G. E. PEARSE 1s.

28 Daily Fatty Acid Excretion. 1960. A. C. FRAZER. 2s.

29 The Preparation of Bone for Diagnostic Histology. 1960. D. H. COLLINS. 2s.

30 Control of Accuracy in Chemical Pathology. 1961. G. H. GRANT. $4 s$.

31 Investigation of Haemorrhagic States with Special Reference to Defects of Coagulation of the Blood. 1961. E. K. BLACKBURN. 4s.

32 Detection of Resistance to Streptomycin, P.A.S., and Isoniazid in Tubercle Bacilli. 1961. R. CRUICKSHANK and S. M. STEWART. 2 s.

33 The Laboratory Detection of Abnormal Haemoglobins. 1961. H. LEHMANN and J. A. M. AGER. 4s.

34 Titration of Antistreptolysin O. 1961. H. GOODER and R. E. O. WILliams. 2s.

35 The Estimation of Faecal 'Urobilinogen.' 1961. c. H. GRAY. $2 s$.

36 Quantitative Determination of Porphobilinogen and Porphyrins in Urine and Faeces. 1961. C. RIMINGTON. 3s. $6 \mathrm{~d}$. 